\title{
Addressing Foreign Language Learning Anxiety with Facebook
}

\author{
Serge Gabarre',2*, Cécile Gabarre1,2, Rosseni Din², Parilah Shah², Aidah Abdul Karim² \\ ${ }^{1}$ Department of Foreign Languages, Universiti Putra Malaysia, Serdang, Malaysia \\ ${ }^{2}$ Faculty of Education, Universiti Kebangsaan Malaysia, Bangi, Malaysia \\ Email: "serge@upm.edu.my
}

Received 3 November 2015; accepted 24 January 2016; published 27 January 2016

Copyright (C) 2016 by authors and Scientific Research Publishing Inc.

This work is licensed under the Creative Commons Attribution International License (CC BY). http://creativecommons.org/licenses/by/4.0/

(c) (i) Open Access

\begin{abstract}
Learning a foreign language can be a daunting task which challenges students in several ways. Although students more readily identify anxiety as linked to speaking, all other language skills have been linked to Krashen's affective filters. The present study sought to address these filters, with an emphasis on anxiety, by incorporating Facebook on mobile phones in the language classroom. A grounded action research method was adopted for the implementation as it enabled the researchers to alter their intervention, and provided a means to systematically analyze the data. A Facebook page and group were introduced to one single cohort of students in their French as a foreign language class. During three semesters, data were collected through online observations and interviews. A three-level coding scheme adhering to Strauss and Corbin's grounded theory enabled the construction of models describing the implementation. Findings revealed that students positively evaluated the incorporation of Facebook in their language course. An assessment of reports linked to anxiety indicated a positive change over the course of the study. Besides reduced levels of anxiety, the use of Facebook was associated with increased self-confidence and motivation. The benefit of learning with friends in an online environment was connected to adaptive strategies leading to improved learning experiences. These findings are discussed in light of the use of a social networking site in a social constructivist perspective.
\end{abstract}

\section{Keywords}

Foreign Language Learning Anxiety, Affect, Social Networking Sites, Mobile Learning

\section{Introduction}

Learning a foreign language is not an easy task. Language students are often challenged with the assimilation of Corresponding author. 
a new lexicon, a different phonologic system, unfamiliar syntax, and communication precepts. As described by Oxford (1999), daunting aspects of foreign language learning are often assimilated with anxiety. For new foreign language learners, speaking is frequently the hardest hurdle in their apprenticeship, however the other skills are not exempt from issues of affect (Cheng, Horwitz, \& Schallert, 1999). The combination of the three factors of motivation, anxiety, and self-confidence form the Affective Filter hypothesis described by Krashen (2009) as well as by Dulay and Burt (1977). These three factors have a positive impact on acquisition as learners with higher motivation and strong self-confidence have the tendency to perform better in a foreign language. Similarly, lower levels of anxiety have a positive impact on language acquisition. The current study focuses on the anxiety affective filter in the context of language learning and language acquisition. Language acquisition is understood through Krashen's acquisition-learning distinction.

Through an action research intervention, the present study aimed to improve as much as possible on the aquisition situation by addressing issues of affect. Krashen posited that the Affective Filter prevents students from being in an optimal attitude for the input to "reach the part of the brain responsible for language acquisition" (2009, p. 31). Consequently, reducing anxiety and increasing motivation and self-confidence limit the Affective Filter which prevents a sufficient level of input from contributing to acquisition. In the present study, the intervention is relevant to affect in four ways. First, using tools and a familiar environment which the students viewed as motivating stimulated them to interact, access and share learning material. Consequently, a reduction of the Affective Filter was able to boost distribution. Second, the development of an online community of practice where students readily communicate in the target language lowered anxiety and increased self-confidence, thus lowering the Affective Filter. Third, empowering the students with some level of control over the distribution process was able to positively impact affect, particularly self-confidence. Fourth, as Krashen (2009) has defended, a reduction in the Affective Filter provided an increased level of input and thus facilitated acquisition of the foreign language.

Studies on social networking sites have demonstrated the potential that such networks hold to positively reduce the affective filters. Overall, the literature reveals a strong tendency towards positive experiences with social networking sites (SNS) in education. This is related to social acceptance in university and learning outcomes as noted by Yu, Tian, Vogel, and Kwok (2010). Furthermore, Kabilan, Ahmad, and Abidin (2010) clearly demonstrated the potential of a popular SNS to promote language learning. For these reasons, it was believed that incorporating an SNS in the foreign language could positively impact the learning process. It was furthermore assumed that this incorporation could be strengthened with the use of a mobile technology.

Mobile learning is a dynamic research field as attested by the numerous review articles on the topic (Ally, 2007; Cochrane, 2010; Godwin-Jones, 2011; Hung \& Zhang, 2012; Keskin \& Metcalf, 2011; Wang \& Shen, 2012). These articles revealed that a majority of experiments demonstrated an accrued effectiveness over traditional methods of learning. This effectiveness impacted the level of learning (Başoğlu \& Akdemir, 2010; Hwang \& Chen, 2011), anxiety (Gabarre \& Gabarre, 2010), motivation (Daher, 2010; Nah, 2011), satisfaction, perceived usefulness, and perceived ease-of-use (Chang \& Hsu, 2011). For these reasons, the effectiveness of m-Learning should no longer be the main focus of research, as this has already been well established. On the other hand, a strong lack of knowledge on the processes that occur outside the classroom remained, and warranted further investigation. The present study addressed this lack of knowledge by focusing on the use of Facebook in a mobile environment.

\section{Methodology}

The action research method was selected for this study as it provided the opportunity to conduct an intervention in the authors' classroom. Action research provided a cyclical approach where results of the action plan were continuously evaluated. This evaluation was systematized by the adoption of grounded theory during the data analysis phases. The combination of action research and grounded theory, known as grounded action research, has demonstrated positive results in several previous studies (Baskerville \& Pries-Heje, 1999; Olson, 2008; Simmons \& Gregory, 2003).

\subsection{Sample}

In accordance with qualitative research sampling techniques (Silverman, 2000), a purposive sampling approach was used whereby one entire cohort of French language students was invited to participate in the present study. 
As such, 17 second-year students enrolled in a Bachelor of French as a foreign language in a Malaysia public university were recruited to participate in group interviews. All ethical requirements set by the university's research management center were adhered to. As parts of such requirements, pseudonyms were attributed to each student in order to protect their identity. Data collected during the group interviews were analyzed and a theoretical sampling selection reduced the number of respondents to three students. A snowballing technique was subsequently used which resulted in increasing the number of respondents to ten. This sample of ten students participated in five cycles of semi-guided individual interviews over the course of the study. The sample was constituted of seven females (three Malays and four Malaysian Chinese) and two males (one Malay and one Malaysian Chinese). Their ages ranged from 20 to 21 years.

\subsection{Action Plan}

The action plan was designed along two axes. First, lecture notes were converted to a mobile-friendly format and posted in the Facebook group where students could readily download them. Second, adhering to guidelines set by Ellis (2000), a task based learning approach was used throughout the study where students were assigned four types of activities. These activities consisted of 1) posting videos of roleplays which they had shot with their mobile phones, 2) posting textual feedback in order to guide their peers to improve their productions, 3) posting short text in response to articles posted on Facebook, and 4) posting comments on French news portal in response to articles posted on the Web. This action plan which incorporated language learning with Facebook on mobile phones is designated as mobile assisted social networking language learning, hereafter abbreviated with the MAS2L acronym.

\subsection{Data Collection}

In the present study, two types of sources were used for the data collection. First, online observations of the exchanges which occurred on the social networking site and on the Web were recorded in an observation grid. This observation grid was designed to record the type of exchange, the language used, the name of the person who initiated the exchange, the type of reply, and the name of the person who replied. A sample of a completed observation grid is available in Appendix A. Second, interviews were conducted to gather rich data pertaining to the students' experience with the action plan. One cycle of group interview was initially conducted with the entire cohort. Subsequently, five cycles of individual interviews were conducted to obtain more specific feedback from the students. This feedback was crucial to revise and improve the action plan as advised by Kemmis and McTaggard (1982).

\subsection{Data Analysis}

The initial step of the data analysis consisted in the transcription of the recorded interviews. For Evers (2011), the transcription process enables the researcher to forge an initial impression on the data, which facilitates the open-coding process. This was methodically carried out on the same day as interviews were conducted. In systematic grounded theory as defined by Strauss and Corbin (1990), open coding refers to the first level coding which occurs as the researcher conducts a line by line assessment of the data. Themes were applied to relevant words or phrases. These themes were then evaluated for similarities with the constant comparative method, and merged to reduce the number of codes to a more manageable number of categories. In the present study, a computer assisted qualitative data analysis software was employed to ease the management of the numerous codes and categories. Based on reviews of several such software (García-Horta \& Guerra-Ramos, 2009), the ATLAS. ti software was selected for its ability to handle vast quantity of data, and for its ease of use. Using this software, a category in relation to the objective of the study was selected as the central category, and then the data were explored in order to discover relationships among the remaining categories. This process where relationships are identified is referred to as axial coding. For this second-level coding, Strauss and Corbin propose five relational links which form the axial coding paradigm. These are the causal condition, the context, the intervening condition, the action/interactional strategies, and the consequence (Strauss \& Corbin, 1990: p. 96). In the present study, this second-level coding resulted in axial coding models which described relevant aspects surrounding themes such as anxiety, foreign language learning, and learning with Facebook. Selective coding, the third level of coding in grounded theory, was employed to obtain an overview of the implementation. With third-level coding scheme, the theme of foreign language learning anxiety with Facebook was articulated. Selective coding 
follows the same coding paradigm as axial coding, but incorporates relationships between axial coding models instead of categories.

\subsection{Validity and Reliability}

In order to ensure that the results of the present study were trustworthy as understood by Lincoln and Guba (1985), three techniques were used. These were 1) member reflections where the respondents were asked to verify that the analysis of the data corresponded with their own experience, 2) triangulation within the same method to ensure that data were consistent, and 3) the use of reflexive memos as an audit trail which provided a traceable account of the proceedings of the study. These three techniques are consistent with those employed in qualitative studies. Member reflection follows the precepts set by Tracy (2010), triangulation adheres to guidelines described by Silverman (2000), and reflexive memos form an integral part of grounded theory as elaborated by Strauss and Corbin (1990).

\section{Findings and Discussion}

The analysis of the data yielded positive findings which highlighted how the use of Facebook on mobile phones addressed issues of affect, and more specifically issues of anxiety. Over the course of the study, students shared their experiences which revealed the strategies they put in place to cope with such issues. Learning with their friends in a networked online environment provided advantages which do not readily occur in the traditional classroom. The following paragraphs illustrate these findings at each of the three level of coding. Verbatim excerpts of interview transcriptions are included to better demonstrate the students' perspectives. Pseudonyms are used throughout the text in order to keep the identity of the students anonymous.

\subsection{Open Coding}

The open coding process was conducted throughout the study as data were collected. After the interview data were transcribed and the observation grids completed, all textual information was reviewed to identify relevant themes. By applying the open coding process, the theme of anxiety was clearly identified in the data. A decrease in anxiety was noted by Annaelle, a student who explained that she initially felt lost when she was confronted to material which she did not understand. However, when faced with practical activities, Annaelle realised that she was capable of carrying them out successfully. As a result, Annaelle was able to understand what she initially could not grasp, and thus felt less anxious. However, issues of anxiety were still reported. Sarah explained that she felt particularly anxious when her oral proficiency was evaluated. The two dimensions of this theme are presented in the following quotes.

Yes, of course, because usually, to be honest, I don't know how to, when you are... when you are show us the PowerPoint, in the beginning I will: "What is this? What is this?" And then, if have the activity, it's help me to... to understand what is actually, the lecturer wants us to learn, the applic, applic, the application... (Annaelle C5:8:127).

I don't know, maybe for Test 2, because Test 2 is more oral things that we actually get nervous when we have to do oral things (Sarah C5:4:217).

Shyness was another such theme which was identified through open coding. Students remarked that they felt less shy to communicate in class. Although the time at which this change occurred was identified as the introduction of the MAS2L platform, students did not spontaneously attribute this change to the new implementation. It was reported that in-class interactions had become more frequent and that students dared express their opinions and ask questions. The following excerpt reveals how Valérie perceived this reduction in shyness over time.

I think it's change a lot, before and now. Because, from when we start coming to [the university], and when we start learning French and we [are] like all quiet and not really talk and speak in class, and also not really interact with lecturer. At the first, maybe level one, level two, French 1, French 2, then after that we, when we start interact, then we feel like: “Ah, it's good." It's more [laugh], more noisy in our class, because we all already dare to speak up our opinion, dare to speak up our question (Valérie C5:3:186).

When applying the constant comparative method, all themes which carried the same meaning were merged 
into a single all-encompassing code. In spite of this, a large number of codes were identified. As prescribed by Creswell (2005), these codes were subsequently combined into categories. Figure 1 illustrates this process, and highlights how codes such as self-confidence, motivation, and joy were combined into the theme of positive affect; whereas shyness and anxiety were combined into the theme of negative affect. Figure 1 depicts how the open coding process enabled the reduction of ten codes into one manageable category. Yet, the open coding process did not reveal any relationship between codes or categories. This was achieved through axial coding.

\subsection{Axial Coding}

The purpose of axial coding is to reconstruct the data which have been deconstructed by the open coding process. With axial coding, categories were reorganised along the relational axes set by Strauss and Corbin (1990). Figure 2 depicts the axial coding diagram resulting from this process, and links affect to improvements. In this diagram affect was placed in a central position and was observed as a consequence of MAS2L within the context of foreign language learning. The theme of learning with friends was identified as the intervening condition to the phenomenon. Indeed, friends provided learning support which proved beneficial in terms of affect. The strategy which was put in place to cope with issues of affect was adaptation. Students adapted in various ways to the situation which affected them in order to surpass their fears, anxieties or low levels of motivation. As a consequence, students felt that they had made progress and improvements in their language proficiency. The themes of learning with friends, adaptation, and improvement are described hereafter with evidence taken from the interviews.

1) Learning with friends. On numerous occasions, students explained how they learned French with their friends from the group. These explanations triangulated with observations and with Adair-Hauck and Donato's (1994) description of learning French within the zone of proximal development (ZPD). More knowledgeable students provided support to those who did not have the same foreign language proficiency. As can be seen in the following triangulated quotations taken from the interviews, assistance was often related to vocabulary enquiries, grammar, and more specifically conjugating verbs. In other cases, assistance from friends took the form of encouragements, explanations, or corrections.

I think I'm the one who always say: "Faster go and study, faster go and study." I'm the one who play the role like this, and they will finally before go to sleep, they will at least they read a bit. But, always like they have, they have problem they will ask. [And then Laurence,] she is, she is the one who tell me: "Check, check again, I think this one wrong already.” She will tell me like that (Valérie C4:1:199,202).

For example there is a new vocabulary, if I know then I will tell them, and also because I'm not so strong in grammar part, Valérie she is strong in grammar part then she will help us if for example we do not understand in which situation or sentences we should use what kind of tenses (Nolwenn C4:3:178). Sometimes the word, the vocab that I forget, I will ask like Marie-Thérèse: "How to say this word? How to say that?” (Chantal C4:4:124).

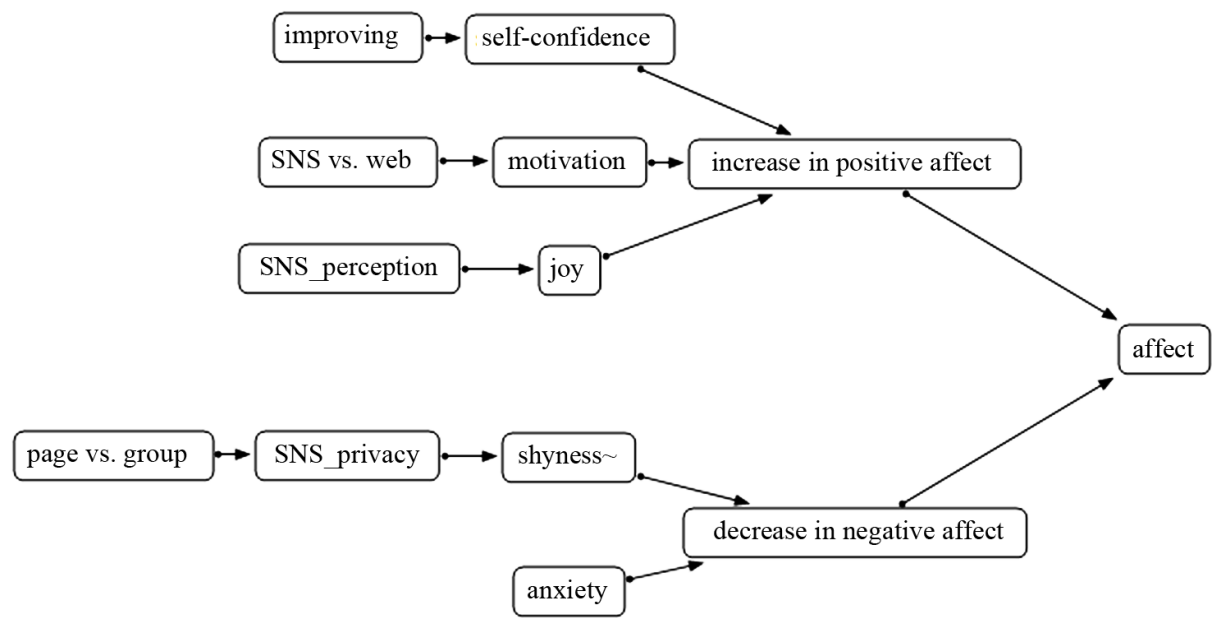

Figure 1. Open coding process of the affect category. 


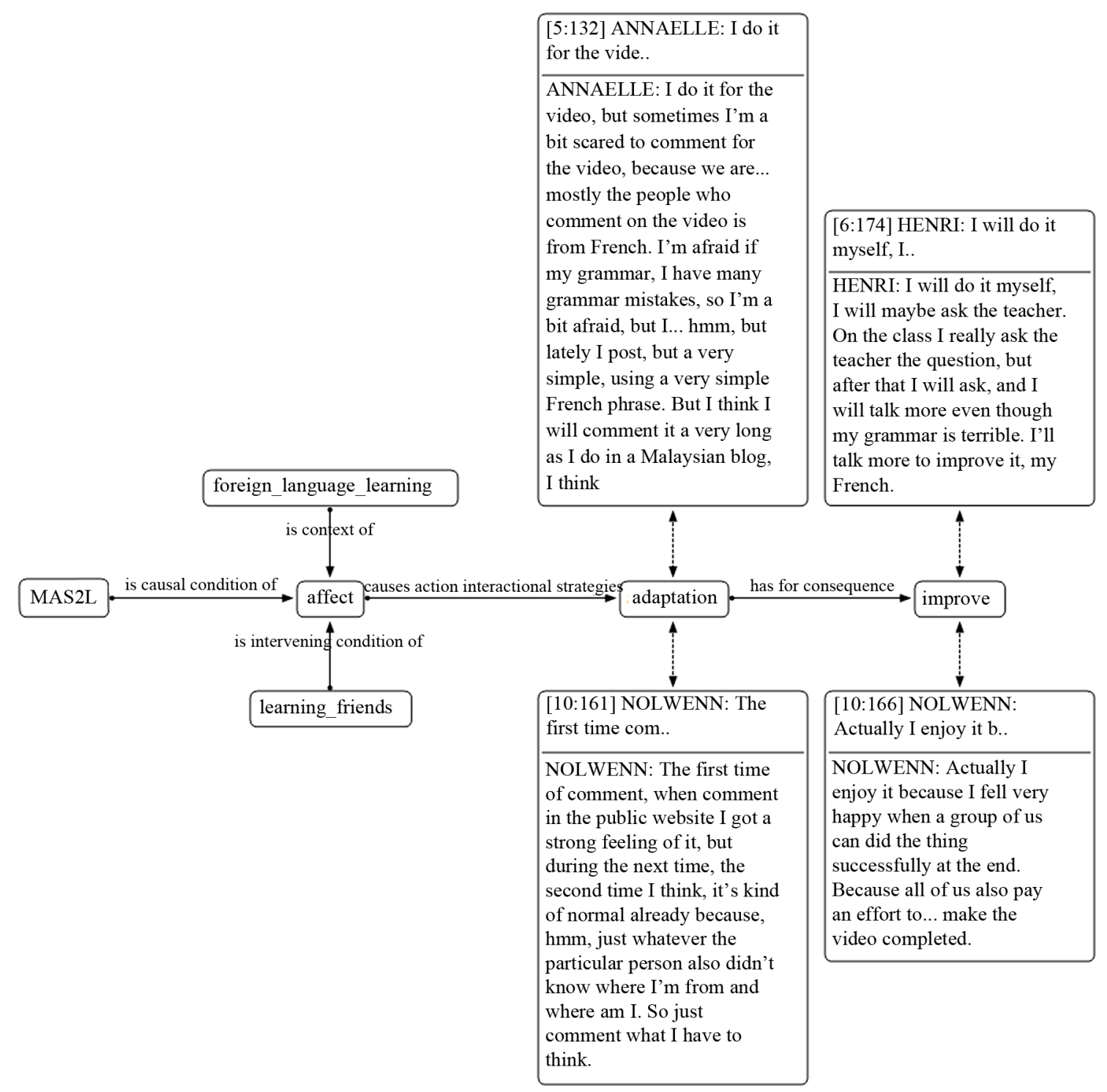

Figure 2. Axial coding of affect leading to improvement.

Sometimes, they ask me, they ask me also the vocabulary and conjugation (Marie-Thérèse C4:2:239).

I speak French with them and also when they ask me how to do the work, I will help. I will help them to finish the work (Ariane C4:5:123).

I will show Valérie my work, then she will correct it, she will explain it back to me, what is wrong, what is right, what is not wrong (Annaelle C4:9:152).

2) Adaptation. When language learning tasks were planned to provide the students with an opportunity to write comments on French news portals, it was envisioned that removing the student from the comfort zone of the SNS would challenge them to excel in applying their communicative skills. This was indeed the case. However, by removing them from their comfort zone, students experienced more anxiety. Annaelle and Nolwenn related their coping mechanisms which they put in place to overcome their distress. Annaelle recalled how she felt about posting a comment on a YouTube video which had been uploaded by a French person. For her, writing a comment was perceived as a frightening task since it would be viewed by Internet users residing in France. Annaelle explained that she feared her grammar would not be correct, and thus would reveal her inadequacies. However, Annaelle adapted to this situation by focussing on simple grammatical structures which she felt she had mastered. With this coping mechanism, Annaelle envisioned posting a longer text, similarly to what she had 
been doing using her native language. Nolwenn's fears were comparable to Annaelle as she felt that her proficiency in French was insufficient to be mistaken for a French Internet user. Yet this feeling was only present during her first post. Nolwenn explained that as she realised that no one knew where she came from, she felt she could freely comment without worrying about such issues. For Henri adapting to issues of low self-confidence encountered during in-class tasks was made possible by focussing on a topic which he felt was interesting, and which he knew he could talk about. For Yolande, fear of taking an exam was resolved when she realised that she was familiar with the format of the evaluation, and that she had been sufficiently exposed to the target language. Yolande explained that this exposure had provided her with the confidence she needed to sit for an international French proficiency exam known as the DELF. Firth and Wagner (2007) view adaptation to a new communicative context as an essential part of the learning process. This view is based on the Doolittle and Hicks (2003) constructivist interpretation that cognition should be envisioned as an adaptive process which results in making the learners more viable in a changing environment. As such, it can be inferred that students participating in the present study adapted to change, and thus learned to communicate in a new and challenging context. The following excerpts provide evidence of this theme.

I do it for the video, but sometimes I'm a bit scared to comment for the video, because we are... mostly the people who comment on the video is from French. I'm afraid if my grammar, I have a very grammar, I have many grammar mistakes, so I'm a bit afraid, but I... hmm, but lately I post, but a very simple, using a very simple French phrase. But, I think I will comment it a very long as I do in a Malaysian blog, I think (Annaelle C6:5:132).

The first time of comment, when comment in the public website I got a strong feeling of it, but during the next time, the second time I think, it's kind of normal already because, hmm, just whatever the particular person also didn't know where I'm from and where am I. So just comment what I have to think (Nolwenn C6:10:161).

I think for the first in the debate I have the problem to talk because my French is not good. I think. I maybe lack of confidence, but the topic for when the debate is, is very interesting (Henri C6:6:205).

Before this I'm afraid to take DELF, but after you [...] expose to us, and post it in Facebook, then the exposure will give us the confidence. Then we, because I think if we are not, if we are not exposed to... to particular test, then we just go, go at that time to sit in the exam. We don't know anything. And, and especially for the, for the language that we don't recognise well, so I think the exposure before the test is good (Yolande C6:9:111).

3) Improvement. As students adapted and overcame their affective inhibitions, they realised that they could communicate in French. Freed from the affective filters described by Krashen (2009), students were able to increase their opportunities to expose themselves to, and practice their skills in the target language. In the following excerpt, Henri explains how in spite of perceived grammar difficulties, he pushed himself to practice his speaking skills. Moreover, he explains how although documents which he was exposed to were beyond his oral comprehension skills, he still persevered in order to grasp key information and improve his pronunciation. Improvements were also reported when students read comments on Facebook, and when they used the language outside of class. The following quotations substantiate the theme of improvement as perceived by the students.

I will talk more even though my grammar is terrible. I'll talk more to improve it, my French [...] Maybe from the Facebook, maybe some trailer from the film. Okay, I will listen to it, okay, how they speak in French? Maybe there are some problems because French native speakers are very fast when speak French, and sometimes I cannot catch what they are trying to say. I sometimes blur, and maybe I listen to it more, many times. Okay, okay, this is, this is, this is, what they are speaking, okay, I can use it to improve my pronunciation also, I think (Henri C6:6:174, 193).

Because if I, you tell us on Facebook, not only me know how to improve, but others also can read the comment, and can also to improve together (Chantal C6:4:111).

Through Facebook, hmm... maybe the way, hmm... because in the group we have to use French to... so even outside class we still have to communicate in French. So, it, it, it will improve our French language (Ariane C6:1:199).

\subsection{Selective Coding}

The selective coding process enabled the emergence of the model represented in Figure 3. This model links 


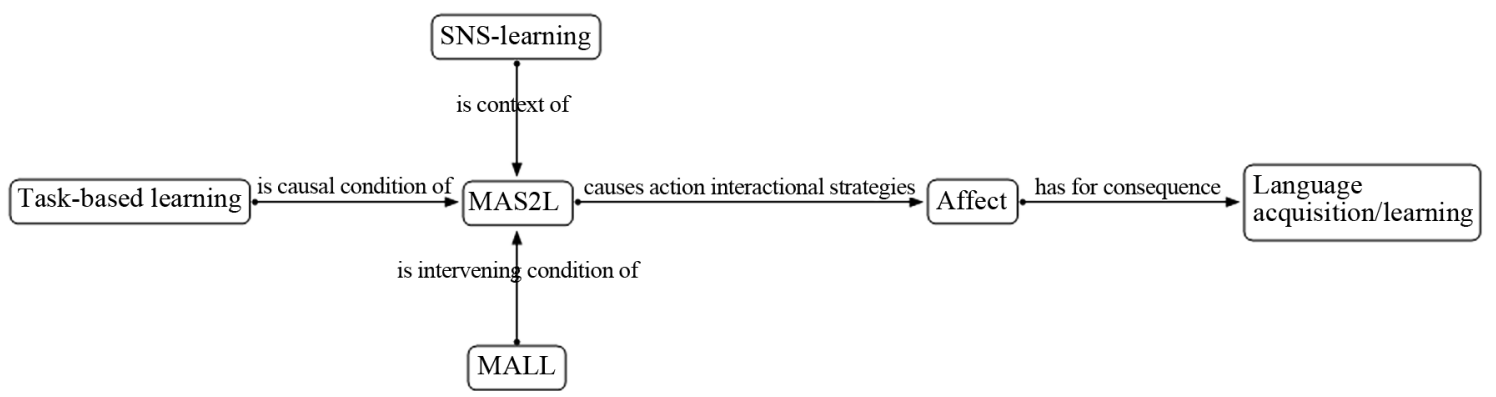

Figure 3. Selective coding diagram.

learning a foreign language on mobile phones and Facebook, to task-based learning, SNS-learning, mobile assisted language learning (MALL), affect, and language acquisition and learning.

Data segments identified the theme of task-based learning category as the causal condition. It is this category which the students perceived as the cause for the MAS2L implementation. This category encompasses themes such as peer correction, learning with friends, as well as college study groups. Students perceive learning as a collective activity which occurred in and out of the classroom. In-class activities which made use of the mobile phones to create documents which were uploaded to the SNS are included in this category. Out-of-class activities where students communicated on the SNS for their tasks, such as posting comments, are also classified in this category.

Both MALL and SNS-Learning were perceived as particularly relevant to the present study. Yet for the students, SNS-Learning appeared as more of a novelty, and as such was reported more predominantly. As an example, friends and families' views of the implementation were repeatedly reported in terms of SNS-Learning, yet MALL did not receive this mention. In this study, the students mainly perceived the MAS2L implementation through its SNS-Learning facet. For these reasons, SNS-Learning was linked to MAS2L as the context of the phenomenon. This category included themes such as SNS and privacy, SNS problems, the compulsive pattern of SNS-Learning, as well as relationships with friends. Similarly to the theme of task-based learning, SNS-Learning includes a strong social constructivist element as students perceived this mode of learning as primarily collectivist.

On the other hand, MALL was associated with individualist learning. For the students, the m-Learning facet of the MAS2L implementation was linked to the delivery of learning material, to location, to selecting between a laptop and a phone, to the notion of ubiquity, and to phone problems, such as issues of connectivity. There was no apparent connection between task-based learning and MALL, in spite of the students using their mobile devices to shoot videos in French as part of their class activities. This task was perceived as relating to SNSLearning as it involved the online peer-feedback element. This view contrasts with Kim and Mangenot's (2009) description of MALL which encompasses delivery as well as the use of tools on the phone for task-based learning. This suggests that the students perceived MALL as a mean to increase their mobility, rather than the techno-centric approach which tends to focus more on the devices.

The affect category was identified in the action/interactional strategies. It includes themes such as frustration, enjoyment, perceived ease, motivation, and self-confidence. It is noteworthy that the theme of anxiety was not included in this category. This theme was insufficiently grounded and did not have enough density. Although anxiety was experienced at times during this study, it appears that students did not perceive it as equally relevant as other themes linked to affect. Of all the themes included in this category, self-confidence was the most grounded with 107 occurrences. This suggests that MAS2L had a significant impact on this affective filter, though additional quantitative studies could evaluate this impact. Both increase in positive affect and decrease in negative affect were included in this category. This reflects the positive view which the students had of the implementation.

The consequence of the MAS2L implementation was identified as the language acquisition/learning category. Data pointed to three themes within this category: 1) foreign language learning, 2) exposure to foreign language, and 3) language acquisition. As was described in the data, students mainly perceived their learning experience through exposure to the target language, and through access to learning material. Language learning was continuously reported throughout the six cycles of implementation, yet students perceived it as more readily related to SNS-Learning and task-based learning than MALL. It was initially anticipated that recourse to the Monitor 
would be conducted through the mobile devices. In-class observations revealed that this was indeed the case, yet interview data did not significantly report this trend. Exposure to the target language was primarily linked to the delivery of lecture notes and to task-based learning. Acquisition was reported whenever students had perceived their improved language proficiency, but remained incapable of describing the processes they had undergone. This theme was linked to task-based learning as well as exposure to the target language.

\section{Conclusion}

Concerning affect, the MAS2L implementation was reported to have increased the students' motivation to access the platform, to learn and to communicate in the target language. Enjoyment was often cited when students described how they felt about using the MAS2L platform. This feeling was linked to communicating with their peers on the SNS, and to reviewing productions, posts, and comments which were regularly published. It was noted that students did not report any anxiety when using the technology. This was also the case with a technophobic student who managed to overcome his initial apprehensions. Using the MAS2L platform, students exhibited a certain level of self-confidence as their proficiency improved. This was particularly visible as students were disappointed that their productions in the target language would not be viewed by friends and family members outside the Facebook group.

For the students, sharing the same virtual network as their lecturers changed the perception of their relationship. Students reported that they felt closer to their lecturers, and that the relationship was comparable to the ones they had with their friends. This concurs with previous findings published by Pasfield-Neofitou (2008) who revealed that the SNS had enabled her to gain more insights on her students' lives and on the way they learned a foreign language. The present study implicated this relationship with reduced anxiety, and increased motivation. After the final cycle of implementation, the lecturers no longer taught the students in the cohort. These students still attended courses in the faculty where they completed their final semester. During this semester, the MAS2L platform was still used for administrative communications. The topic of these communications was mainly the upcoming DELF exams which several students passed successfully. Peer exchanges were still recorded two months after the end of the last cycle. In one such instance, the MAS2L platform was used to send a distress message to the group. Valérie, while out with three other classmates, happened to experience car difficulties when her fuel tank became empty. She promptly used her phone to post a message on the French course's platform, and requested for help. Replies from other classmates were shortly answered, and someone came to assist them. This event highlights the students' perception of the MAS2L platform as a mean to rapidly and effectively communicate with their peers. These exchanges revealed that all communications were conducted in French. It is noteworthy to emphasize that even after the end of the implementation, students still used the platform to communicate in the target language, even during an event which was considered as an emergency.

Four main limitations to this study need to be highlighted. First, due to the qualitative nature of the grounded action research and to the absence of a randomized sampling method, findings may not be generalized to the whole population. Second, although the duality of the role of the researcher as the cohort's lecturer was taken into account during the data analysis phase, interferences may have unknowingly occurred. Third, as a consequence of financial constraints, data collection was limited to a period of one and a half year. Fourth, the lack of students engaged in a bachelor degree in French in Malaysia limited the study to a single site.

In order to provide this qualitative study with quantifiable results, it is suggested that future studies could address the same issues through quantitative paradigm. These studies could measure the impact of using Facebook on mobile device on anxiety, self-confidence and motivation. Additionally, further studies could seek to validate the present study by changing specific variables such as the context, the language learned, the SNS used, or the age of the participants.

\section{References}

Adair-Hauck, B., \& Donato, R. (1994). Foreign Language Explanations within the Zone of Proximal Development. Canadian Modern Language Review, 50, 532-557.

Ally, M. (2007). Mobile Learning. International Review of Research in Open and Distance Learning, 8, 1-4.

Baskerville, R., \& Pries-Heje, J. (1999). Grounded Action Research: A Method for Understanding IT in Practice. Accounting Management and Information Technologies, 9, 1-23. http://dx.doi.org/10.1016/S0959-8022(98)00017-4

Başoğlu, E. B., \& Akdemir, Ö. (2010). A Comparison of Undergraduate Students’ English Vocabulary Learning: Using Mo- 
bile Phones and Flash Cards. The Turkish Online Journal of Educational Technology, 9, 1-7.

Chang, C.-K., \& Hsu, C.-K. (2011). A Mobile-Assisted Synchronously Collaborative Translation-Annotation System for English as a Foreign Language (EFL) Reading Comprehension. Computer Assisted Language Learning, 24, $155-180$. http://dx.doi.org/10.1080/09588221.2010.536952

Cheng, Y., Horwitz, E., \& Schallert, D. (1999). Language Anxiety: Differentiating Writing and Speaking Components. Language Learning, 49, 417-446. http://dx.doi.org/10.1111/0023-8333.00095

Cochrane, T. D. (2010). Beyond the Yellow Brick Road: Mobile Web 2.0 Informing a New Institutional E-Learning Strategy. Research in Learning Technology, 18, 221-231. http://dx.doi.org/10.1080/09687769.2010.529110

Creswell, J. W. (2005). Educational Research: Planning, Conducting, and Evaluating Quantitative and Qualitative Research. Upper Saddle River, NJ: Pearson Education.

Daher, W. (2010). Building Mathematical Knowledge in an Authentic Mobile Phone Environment. Australasian Journal of Educational Technology, 26, 85-104.

Doolittle, P. E., \& Hicks, D. (2003). Constructivism as a Theoretical Foundation for the Use of Technology in Social Studies. Theory \& Research in Social Education, 31, 72-104. http://dx.doi.org/10.1080/00933104.2003.10473216

Dulay, H., \& Burt, M. (1977). Remarks on Creativity in Language Acquisition. In M. Burt, H. Dulay \& M. Finnochiaro (Eds.), Viewpoints on English as a Second Language (pp. 95-126). New York: Regents.

Ellis, R. (2000). Task-Based Research and Language Pedagogy. Language Teaching Research, 193, 193-220. http://dx.doi.org/10.1177/136216880000400302

Evers, J. C. (2011). From the Past into the Future. How Technological Developments Change Our Ways of Data Collection, Transcription and Analysis. Forum Qualitative Sozialforschung/Forum: Qualitative Social Research, 12.

Firth, A., \& Wagner, J. (2007). Second/Foreign Language Learning as a Social Accomplishment: Elaborations on a Reconceptualized SLA. The Modern Language Journal, 91, 800-819. http://dx.doi.org/10.1111/j.1540-4781.2007.00670.x

Gabarre, S., \& Gabarre, C. (2010). Shooting Short Videos in French with Mobile Phones. FULGOR, 4, 93-108.

García-Horta, J. B., \& Guerra-Ramos, M. T. (2009). The Use of CAQDAS in Educational Research: Some Advantages, Limitations and Potential Risks. International Journal of Research \& Method in Education, 32, 151-165. http://dx.doi.org/10.1080/17437270902946686

Godwin-Jones, R. (2011). Emerging Technologies: Mobile Apps for Language Learning. Language Learning \& Technology, 15, 2-11.

Hung, J.-L., \& Zhang, K. (2012). Examining Mobile Learning Trends 2003-2008: A Categorical Meta-Trend Analysis Using Text Mining. Journal of Computing in Higher Education, 24, 1-17. http://dx.doi.org/10.1007/s12528-011-9044-9

Hwang, W.-Y., \& Chen, H. (2011). Users' Familiar Situational Contexts Facilitate the Practice of EFL in Elementary Schools with Mobile Devices. Computer Assisted Language Learning, 1-25.

Kabilan, M. K., Ahmad, N., \& Abidin, M. J. Z. (2010). Facebook: An Online Environment for Learning of English in Institutions of Higher Education? Internet and Higher Education, 13, 179-187. http://dx.doi.org/10.1016/j.iheduc.2010.07.003

Kemmis, S., \& McTaggart, R. (1982). The Action Research Planner. Victoria: Deakin University Press.

Keskin, N. O., \& Metcalf, D. (2011). The Current Perspectives, Theories and Practices of Mobile Learning. The Turkish Online Journal of Educational Technology, 10, 202-208.

Kim, H.-K., \& Mangenot, F. (2009). Apprentissage Nomadeen Langue et Production Orale Asynchrone [Mobile Learning in Languages and Asynchronous Oral Production]. Proceedings of the Epal 2009 Conference, Grenoble, 4-6 June 2009, $1-17$.

Krashen, S. D. (2009). Principles and Practice in Second Language Acquisition. Oxford: Pergamon Press Inc.

Lincoln, Y. S., \& Guba, E. G. (1985). Naturalistic Inquiry. Thousand Oaks, CA: Sage.

Nah, K. C. (2011). Optimising the Use of Wireless Application Protocol (WAP) Sites for Listening Activities in a Korean English as a Foreign Language (EFL) Context. Computer Assisted Language Learning, 24, 103-116. http://dx.doi.org/10.1080/09588221.2010.526946

Olson, M. M. (2008). Using Grounded Action Methodology for Student Intervention-Driven Succeeding: A Grounded Action Study in Adult Education. Forum Qualitative Sozialforschung/Forum: Qualitative Social Research, 9, 1-21.

Oxford, R. (1999). Anxiety and the Language Learner: New Insights. In J. Arnold (Ed.), Affect in Language Learning (pp. 58-67). Cambridge, UK: Cambridge University Press.

Pasfield-Neofitou, S. E. (2008). Creative Applications of Social Networking for the Language Learning Class. The International Journal of Learning, 14, 235-239.

Silverman, D. (2000). Doing Qualitative Research. Thousand Oaks, CA: Sage. 
Simmons, O. E., \& Gregory, T. A. (2003). Grounded Action: Achieving Optimal and Sustainable Change. Forum Qualitative Sozialforschung/Forum: Qualitative Social Research, 4, 1-17.

Strauss, A. L., \& Corbin, J. (1990). Basics of Qualitative Research: Grounded Theory Procedures and Techniques. Thousand Oaks, CA: Sage.

Tracy, S. J. (2010). Qualitative Quality: Eight “Big-Tent” Criteria for Excellent Qualitative Research. Qualitative Inquiry, 16, 837-851. http://dx.doi.org/10.1177/1077800410383121

Wang, M., \& Shen, R. (2012). Message Design for Mobile Learning: Learning Theories, Human Cognition and Design Principles. British Journal of Educational Technology, 43, 561-575. http://dx.doi.org/10.1111/j.1467-8535.2011.01214.X

Yu, A. Y., Tian, S. W., Vogel, D., \& Kwok, R. C.-W. (2010). Can Learning Be Virtually Boosted? An Investigation of Online Social Networking Impacts. Computers \& Education, 55, 1494-1503.

http://dx.doi.org/10.1016/j.compedu.2010.06.015 


\section{Appendix A}

\section{Sample observation grid}

Cycle:

$1 \mathrm{~B}$

Week in of the cycle: 3

Week in the semester: 10

Course: Introduction to French culture

\begin{tabular}{|c|c|c|c|c|}
\hline Respondent & Language & Spontaneous/Response & Description & Liked by \\
\hline Zoé & French & Spontaneous & Posted a video preview of a French film & $\begin{array}{c}\text { Marie-Thérèse } \\
\text { Julie } \\
\text { Annaelle }\end{array}$ \\
\hline Valérie & English & Response to Zoé & Thanking & Zoé \\
\hline Corinne & French & Response to Zoé & Thanking & Annaelle \\
\hline Julie & French & Response to Zoé & Thanking & \\
\hline Zoé & N/A & Additional info & Posted a link to download the same French film & \\
\hline Zoé & N/A & Additional info & Posted a link to download the same French film & \\
\hline Researcher & French & Response to Zoé & Additional info & Zoé \\
\hline Respondent & Language & Spontaneous/Response & Description & Liked by \\
\hline Zoé & French & Spontaneous & Posted a video preview of a second French film & $\begin{array}{c}\text { Corinne } \\
\text { Annaelle } \\
\text { Ariane }\end{array}$ \\
\hline Ariane & French & Response to Zoé & Thanking & \\
\hline Zoé & French & Response to Ariane & Thanking & \\
\hline Zoé & English & Additional info & Has finished downloading the video & \\
\hline Ariane & Malay & Response to Zoé & Informs will get the video from Zoé & \\
\hline Zoé & English & Response to Ariane & Agrees & \\
\hline Researcher & French & Response to Zoé & Additional info & $\begin{array}{l}\text { Ariane } \\
\text { Zoé }\end{array}$ \\
\hline
\end{tabular}

